\title{
Cross-modal attentional deficits in processing tactile stimulation
}

\author{
ROBERTO DELL'ACQUA and MASSIMO TURATTO \\ University of Padua, Padua, Italy \\ and \\ PIERRE JOLICGEUR \\ University of Waterloo, Waterloo, Ontario, Canada
}

\begin{abstract}
In order to substantiate recent theorization on the possible links between the causes of the attentional blink and the psychological refractory period phenomena (e.g., Jolicour, 1999a), four experiments are reported in which two target stimuli, $\mathrm{T}_{1}$ and $\mathrm{T}_{2}$, were presented in different modalities at varying stimulus onset asynchronies (SOAs), with each stimulus being associated with a distinct task,

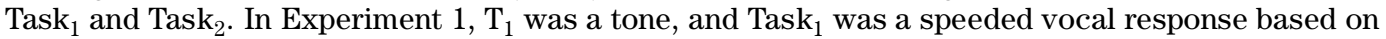

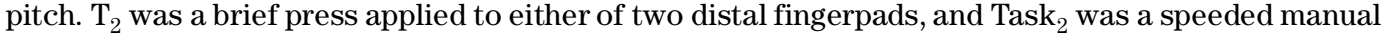
response based on tactile stimulus location. In Experiment 2, the same $\mathrm{T}_{1}$ as that used in Experiment 1 was presented, and in Task $\mathrm{k}_{1}$ the subject either made a speeded vocal response based on pitch or ignored $\mathrm{T}_{1}$. $\mathrm{T}_{2}$ was a masked tactile stimulation, and Task $\mathrm{T}_{2}$ was an unspeeded manual discrimination of the tactile stimulation location. This Task $\mathrm{K}_{2}$ was maintained in Experiments 3 and 4 . The auditory $\mathrm{T}_{1}$ was replaced with a white digit embedded in a rapid serial visualization presentation of a stream of black let-

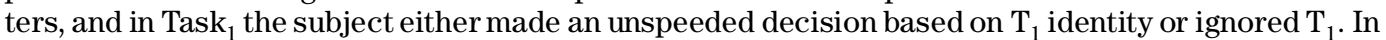
all the experiments, the results showed an SOA-locked impairment in Task 2 . As SOA was decreased, reaction times in the speeded Task ${ }_{2}$ of Experiment 1 increased, and accuracy in the unspeeded Task ${ }_{2}$ of Experiments 2-4 decreased. The SOA-locked impairment was almost eliminated when $\mathrm{T}_{1}$ could be ignored or was absent. The results are discussed in terms of central processing limitations as the cause of such effects.
\end{abstract}

When two target stimuli, $\mathrm{T}_{1}$ and $\mathrm{T}_{2}$, are presented at brief temporal intervals and each stimulus requires a distinct response, two different types of interference in the processing of $T_{2}$ are normally found. When both stimuli are unmasked and an immediate response is required for each stimulus, an increase in reaction times (RTs) to $T_{2}$ as the temporal interval between the onsets of the stimuli (SOA) is decreased is pervasively reported in the literature. This effect is often called the psychological refractory period (PRP) effect, after Telford (1931; see Pashler, 1994, for a review). A different type of dual-task interference is reported for conditions in which both stimuli are masked and an unspeeded response is required for each stimulus. The results from these conditions often show a reduction in $\mathrm{T}_{2}$ response accuracy when the SOA between the stimuli is less than half a second. This second type of dual-task interference has been

This work was supported by START-UP Grant FFMA 98 from the University of Padua to R.D. and by a grant from the Natural Sciences and Engineering Research Council of Canada to P.J. We are indebted to Ray Klein, Remo Job, Hal Pashler, Kimron Shapiro, Carlo Umiltà, and one anonymous reviewer for valuable comments on previous versions of this manuscript. Correspondence concerning this article should be addressed to R. Dell' Acqua, Dipartimento di Psicologia, Via Venezia, 8, 35131 Padova, Italy (e-mail: dellacqu@ psy.unipd.it). labeled an attentional blink (AB) effect (Raymond, Shapiro, \& Arnell, 1992, 1995; see also Broadbent \& Broadbent, 1987; Chun, 1997; Chun \& Potter, 1995; Duncan, Martens, \& Ward, 1997; Jolicœur, 1999b; Moore, Egeth, Berglan, \& Luck, 1996).

Some researchers interpret the observed interference between tasks as evidence that central (i.e., postperceptual and premotor) mechanisms carrying out certain critical operations cannot be shared across tasks. When these mechanisms are required for two such tasks, they act as a structural bottleneck in the flow of processing, and dualtask interference results in conditions of high temporal overlap between the tasks (e.g., Pashler \& Johnston, 1989). In PRP paradigms, one of these critical operations has been indicated in response selection (McCann \& Johnston, 1992; Pashler \& Johnston, 1989; Schubert, 1999; Van Selst \& Jolicœur, 1997).

A formally analogous explanation has recently been advanced to explain the cause of the AB effect (Arnell \& Jolicœur, 1999; Jolicœur, 1998; Jolicœur, Dell'Acqua, \& Crebolder, 2000). In AB paradigms, however, the central operations generating the bottleneck have been hypothesized to involve a stage of short-term consolidation (Jolicœur \& Dell'Acqua, 1998) for the storage of information in short-term memory. Chun and Potter (1995) proposed a similar explanation for the $\mathrm{AB}$ effect—namely, a bottle- 
neck in short-term consolidation-arguing, however, that the $\mathrm{AB}$ effect and the PRP effect have different and distinct causes.

Two key predictions bearing on the issue of functional similarity in the causes of PRP and AB effects have been tested in the literature. One prediction is derived from the notion that the engagement of central, modalityindependent, mechanisms causes both effects. In this view, $P R P$ and $A B$ effects are expected to affect human performance in conditions in which $\mathrm{T}_{1}$ and $\mathrm{T}_{2}$ are presented in the same sensory modality, as well as in conditions in which $T_{1}$ and $T_{2}$ are presented in different sensory modalities. Several PRP studies have generated results consistent with this assumption (e.g., De Jong, 1993; see Pashler \& Johnston, 1998, for a review). Furthermore, this prediction has recently been confirmed for the AB paradigm. Arnell and Jolicœur (1999, Experiment 1, p. 632) had subjects experience simultaneous streams of visual and auditory stimuli. The visual stimuli were black characters presented one at the time, in the same spatial location, for a duration of $93.3 \mathrm{msec}$ each. Auditory stimuli were spoken letters compressed to a duration of $90 \mathrm{msec}$. In the critical conditions, the subjects had to monitor one sensory modality for a to-be-identified number $\left(\mathrm{T}_{1}\right)$ presented among letter distractors and the other sensory modality for the presence of an $X\left(T_{2}\right)$, which was presented with a probability of .5 on each trial. In this experiment, a group of subjects was presented with $\mathrm{T}_{1}$ in the auditory modality and $\mathrm{T}_{2}$ in the visual modality. A different group of subjects was presented with $T_{1}$ in the visual modality and $\mathrm{T}_{2}$ in the auditory modality. The results in both conditions revealed a typical $\mathrm{AB}$ effectthat is, $\mathrm{T}_{2}$ response accuracy decreased as the $\mathrm{T}_{1}-\mathrm{T}_{2} \mathrm{SOA}$ was reduced to less than 500-600 msec. Similar results have been reported by Shulman and Hsieh (1995) and Potter, Chun, Banks, and Muckenhoupt (1998).

The second prediction is derived from the hypothesis that central processing is involved both in a speeded task requiring response selection and in an unspeeded task requiring short-term consolidation. According to this hypothesis, dual-task interference should be evident in conditions in which a speeded response to an unmasked $\mathrm{T}_{1}$ is combined with an unspeeded response to a masked $\mathrm{T}_{2}$. Dell' Acqua and Jolicœur (2000; see also Jolicœur, 1999b) tested this prediction by presenting subjects with a 100msec pure tone with two possible frequencies as $T_{1}$ and a visually presented 150 -msec masked matrix of randomly arranged red squares as $T_{2} . T_{1}$ required a speeded choice response based on pitch, and $\mathrm{T}_{2}$ required an unspeeded same/different judgment between the masked matrix and a second matrix presented in free-viewing conditions at the end of the trial. The results showed an AB effect. Accuracy in the same/different judgment task decreased as the SOA between $T_{1}$ and $T_{2}$ decreased from 900 to $150 \mathrm{msec}$. Further evidence for the involvement of central mechanisms in the cause of this $\mathrm{AB}$ effect was provided by manipulating the number of response alterna- tives in Task $_{1}$, a variable hypothesized to affect primarily the time taken to carry out response selection in a speeded task (Karlin \& Kestenbaum, 1968; Schubert, 1999; Van Selst \& Jolicœur, 1997). When the number of alternatives was manipulated in Task ${ }_{1}$, a clear modulation of the $\mathrm{AB}$ effect was found in Task 2 at the shortest SOA, in the form of a magnified $\mathrm{AB}$ effect as the number of Task ${ }_{1}$ response alternatives was increased.

Interestingly, the majority of the studies investigating PRP and $A B$ effects have essentially revolved around two sensory modalities, the visual modality and the auditory modality. The aim of the present work is to investigate dual-task processing interactions that occur for stimuli presented in a different sensory modality-namely, taction. To our knowledge, in fact, no PRP studies have investigated cross-modal processing interactions involving the presentation of stimuli in the tactile modality (but see Brebner, 1977, for the only reported experiment in which two tactile stimuli were used in a same-modality PRP paradigm). Only one study explored tactile stimulation in the context of the AB paradigm (Shapiro, Hillstrom, \& Spence, 1998). Although all extant models of the PRP effect predict PRP effects with tactile stimuli, additional research on taction in dual-task paradigms is warranted by the fact that Shapiro et al. reported null evidence for tactile $\mathrm{AB}$ effects in several experiments.

The present study is organized as follows. In Experiment 1 , we employed a dual-task paradigm to confirm the prediction that a robust PRP effect should occur even when one stimulus is auditory and one is tactile. Subjects were presented with a pure tone as $\mathrm{T}_{1}$ and were required to perform a speeded classification of its pitch (high vs. low). A brief tactile stimulus was presented to the distal pad of either the index finger or the middle finger of the left hand as $\mathrm{T}_{2}$, and the subjects were required to perform a speeded response based on tactile stimulus location (i.e., which finger). In Experiment 2, using a paradigm that bears a close resemblance with those used by Dell'Acqua and Jolicœur (2000), we investigated whether a tactile $\mathrm{AB}$ could be found in conditions in which Task ${ }_{1}$ required the subjects either to make the same speeded auditory classification as that implemented in Experiment 1 or to ignore $\mathrm{T}_{1}$. The tactile task involved an unspeeded response based on the starting location of a stream of tactile stimuli presented as $T_{2}$. To minimize possible interference effects at the level of motor output (e.g., Van Selst, Ruthruff, \& Johnston, 1999), responses to $\mathrm{T}_{1}$ in Experiments 1 and 2 were always emitted vocally, and responses to $T_{2}$ were always emitted manually. Experiments 3 and 4 were designed to test whether a tactile $A B$ could be found in conditions that more strictly pertain to classical $\mathrm{AB}$ paradigms, in which unspeeded responses to both $\mathrm{T}_{1}$ and $T_{2}$ are typically required. $T_{1}$ was a visually presented digit embedded in a rapid serial visualization presentation (RSVP) of letters, and Task ${ }_{1}$ required subjects either to make an unspeeded odd/even decision on $\mathrm{T}_{1}$ at the end of the RSVP or to ignore $\mathrm{T}_{1}$. The same $\mathrm{T}_{2}$ and Task 2 
as those used in Experiment 2 were used in Experiments 3 and 4 . Experiment 4 was thought of as a control condition for the $\mathrm{AB}$ effects investigated in Experiment 3. The variant introduced in Experiment 4 was to present $T_{1}$ randomly on $50 \%$ of the trials during the experiment, in order to evaluate the impact of task-switch cost (e.g., Rogers \& Monsell, 1995) on Task $_{2}$ performance. To anticipate, a robust PRP effect was found in Experiment 1. Clear-cut evidence for tactile $\mathrm{AB}$ effects was found in both Experiment 2 and Experiment 3 when Task ${ }_{1}$ required processing of $\mathrm{T}_{1}$. Experiment 4 showed that at least part of the costs associated with processing close-to-concurrent cross-modal stimuli could not be attributed to differences in the tasks employed in the present investigation.

\section{EXPERIMENT 1}

\section{Method}

Subjects. Six students at the University of Padua volunteered to participate in the present experiment. All were undergraduate students, with ages ranging from 20 to 30 years. All were naive as to the purpose of the experiment, and all reported normal taction and normal hearing.

Auditory stimuli. The auditory stimuli were pure tones, presented for $100 \mathrm{msec}$, with a frequency of 400 or $1200 \mathrm{~Hz}$. The auditory stimuli were presented through the speakers of a computer, at a volume of about $50 \mathrm{~dB}$.

Tactile stimuli. The tactile stimuli were single presses applied to the distal pad of the index finger or the middle finger of the left hand. The apparatus for the generation of the tactile stimuli consisted of two RS tactile stimulators fit against the distal pads of the index and middle fingers, which were embedded in foam material to reduce the noise generated by their functioning. Each display consisted of a miniaturized solenoid $(3 \mathrm{~W}, \pm 12 \mathrm{~V}$ ) with a moving cylindrical metallic plunger, $1.4 \mathrm{~mm}$ in diameter and $50 \mathrm{~mm}$ in length, that was oriented perpendicularly to the pad of each finger. The two stimulators could be activated independently, allowing us to stimulate the index or the middle finger. Upon activation, the plunger of a given stimulator moved $4 \mathrm{~mm}$ vertically for $100 \mathrm{msec}$ and touched the fingerpad. A $686 \mathrm{CPU}$ controlled the tactile stimulators, the duration and sequencing of the tactile stimuli, as well as a visual monitor that was used to give instructions and feedback to the subjects.

Procedure. The subjects were seated with both arms resting on the table in front of them, facing a computer monitor. On each trial of the present experiment, one auditory stimulus, $\mathrm{T}_{1}$, and one tactile stimulus, $T_{2}$, were presented in succession, with each stimulus requiring a distinct speeded response. The subscript refers to stimuli order of arrival, so that $\mathrm{T}_{1}$ was always the first stimulus, followed by $\mathrm{T}_{2}$. Each trial began with the presentation of a fixation cross at the center of the monitor, which remained on the screen during the entire trial. A research assistant initiated each trial by pressing a key on a response box. After this keypress, a fixed temporal interval of $600 \mathrm{msec}$ elapsed before the presentation of $\mathrm{T}_{1}$. The subjects were instructed to make an immediate, vocal, twoalternative choice response based on the pitch of $\mathrm{T}_{1}$, by saying "high" if the pitch of $\mathrm{T}_{1}$ was high or "low" if the pitch of $\mathrm{T}_{1}$ was low. RTs to $\mathrm{T}_{1}$ were measured with a voice key and a microphone placed about $5 \mathrm{~cm}$ in front of the subject's mouth. The auditory-vocal task, Task ${ }_{1}$, was defined as the primary task, and both speed and accuracy were emphasized in the instructions. During the entire experiment, the research assistant scored the vocal responses for accuracy.

At one of three possible SOAs $(100,250 \text {, or } 900 \mathrm{msec})^{1}$ following the tone, $\mathrm{T}_{2}$ was presented to either the index finger or the mid- dle finger of the left hand. The subjects were instructed to make an immediate, manual, two-alternative choice response based on $\mathrm{T}_{2}$ location, by pressing the " 1 " key of the computer numeric keypad if $\mathrm{T}_{2}$ was presented to the middle finger or the " 2 " key of the computer numeric keypad if $\mathrm{T}_{2}$ was presented to the index finger. Presses to " 1 " and "2" keys were to be made by using the index finger and the middle finger of the right hand, respectively. Pilot work had indicated that this particular stimulus-response mapping was one that subjects found most natural, presumably for the spatial correspondence (left vs. right) of stimulus and response locations. The subjects were strongly encouraged to also perform the tactile-manual task, Task $_{2}$, as fast and accurately as they could.

Two distinct sessions preceded the data-recording session. In the first session, the microphone sensitivity was set according to each subject's vocal characteristics. A random sequence of 10 tones with frequencies of either 400 or $1200 \mathrm{~Hz}$ was presented to each subject. The subjects were instructed to say, as fast and accurately as possible, "high" for the high-pitch tone or "low" for the low-pitch tone, while trying to avoid noise (e.g., coughs) or hesitations (e.g., "hum ..."). The sequence of tones was repeated in case one or more failures to detect the vocal response occurred. The sensitivity of the voice key was adjusted so that no responses were missed and very few spurious triggerings were observed. The subjects performed 2 blocks of 24 dual-task trials each. At the end of the practice session, the instructions were repeated, and each subject performed 10 blocks of 24 trials each. Levels of SOA, tone frequency, and $\mathrm{T}_{2}$ location were fully crossed within each block of trials. At the end of each experimental block, each subject was provided with feedback on his/her mean Task 1 RT and mean Task ${ }_{2}$ RT through written information reported on the computer monitor.

\section{Results}

The analyses concentrated on correct RTs and error rates in Task ${ }_{1}$ and correct RTs and error rates in Task ${ }_{2}$. Correct RTs in each task were screened for outliers, using a modification of the procedure described by Van Selst and Jolicœur (1994). ${ }^{2}$ When one outlier (or an error) was found in one or both tasks, the entire trial was excluded from further analysis. The application of the outlier elimination procedure on the present data set resulted in a total loss of $2.6 \%$ of correct RTs. The results from both tasks were analyzed with an analysis of variance (ANOVA), in which SOA was treated as a within-subjects variable.

Task . Mean RTs in Task $_{1}$, as a function of SOA, are reported in Figure 1 (circular symbols). The mean $\mathrm{RT}_{1}$ was $578 \mathrm{msec}$. The SOA effect was not significant $[F(2,10)=$ $\left.1.0, M S_{\mathrm{e}}=805, p>.39\right]$.

The mean error rate in Task $_{1}$ was $7 \%$. The SOA effect was not significant $(F<1)$.

Task $_{2}$. Mean RTs in Task 2 , as a function of SOA, are reported in Figure 1 (square symbols). The mean $\mathrm{RT}_{2}$ was $715 \mathrm{msec}$. The effect of SOA was highly significant $\left[F(2,10)=65.2, M S_{\mathrm{e}}=2,793, p<.001\right]$, reflecting a progressive increase in $\mathrm{RT}_{2}$ as SOA was decreased.

The mean error rate in Task 2 was $12 \%$. The SOA effect was not significant $(F<1)$.

\section{Discussion}

The results of Experiment 1 revealed a typical PRP effect in conditions in which two unmasked stimuli, one auditory and one tactile, were each associated with dis- 


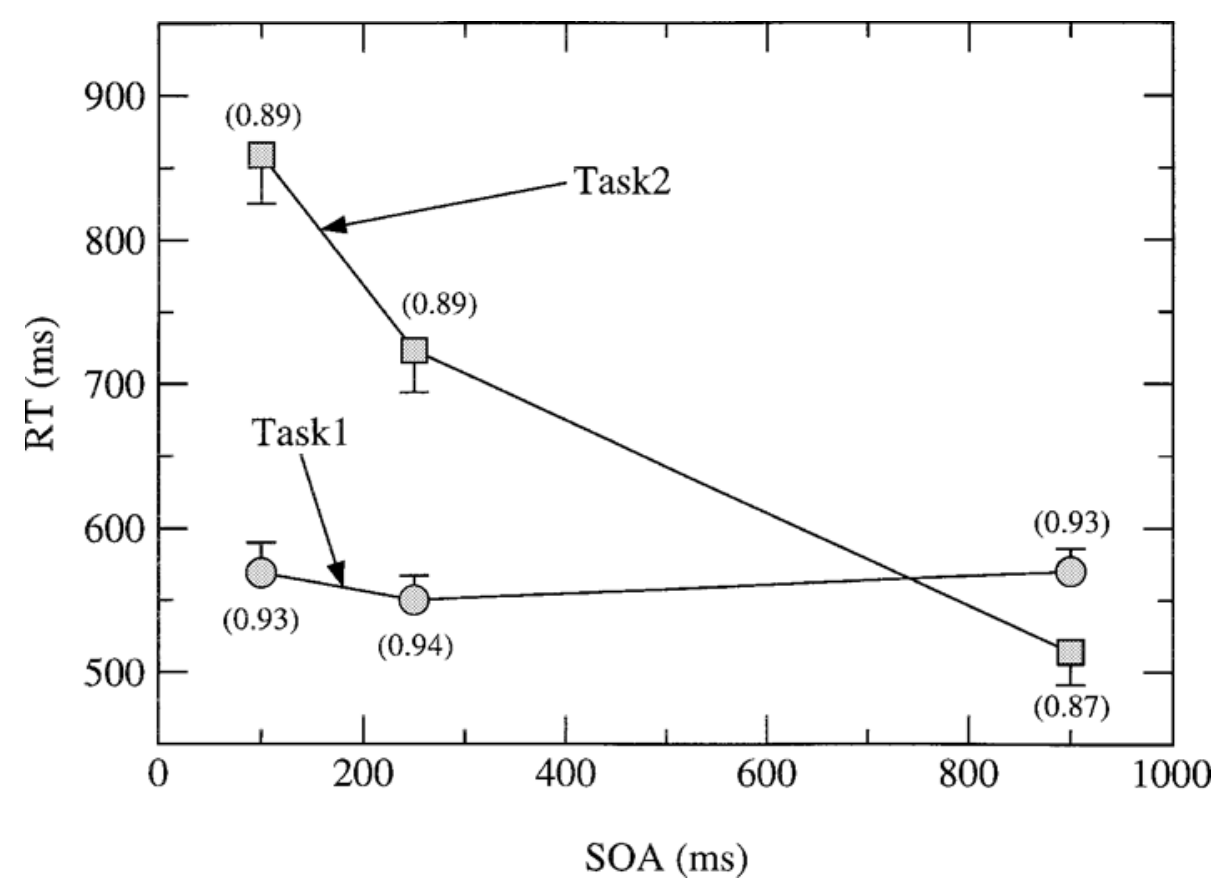

Figure 1. Results from Experiment 1: Mean reaction times (RTs) in the auditory-vocal Task (circular symbols) and mean RTs in the tactile-manual Task ${ }_{2}$ (square symbols), as a function of stimulus onset asynchrony (SOA). The proportion of correct responses in each task and SOA condition is reported in parentheses. Vertical bars show standard errors of the mean.

tinct two-choice speeded tasks. As SOA decreased, RTs in Task ${ }_{1}$ remained constant, and RTs in Task 2 progressively increased, with a slope at the two shorter SOAs of -.92 . This value nicely approaches the ideal -1.0 slope argued to be a hallmark of "pure" postponement of Task 2 responses in this type of paradigm (see Pashler, 1994).

\section{EXPERIMENT 2}

The rationale for Experiment 2 was as follows. If a functional component of the $\mathrm{AB}$ effect is tied to similar processing limitations as those causing the PRP effect, an AB-like pattern of results should be observed in a paradigm in which Task ${ }_{1}$ requires a speeded response to an auditory $T_{1}$ and Task ${ }_{2}$ requires an unspeeded response to a masked tactile stimulus presented in $\mathrm{T}_{2}$. Furthermore, an $\mathrm{AB}$ should not be observed if $\mathrm{T}_{1}$ can be ignored. Following Craig's (1989) indications, a technique was developed to provide efficient masking of the tactile $T_{2}$. In the same vein as in RSVP paradigms, a stream of tactile stimuli was employed for $\mathrm{T}_{2}$ presentation, instead of the single tactile stimulus used in Experiment $1 . \mathrm{T}_{2}$ was a sequence of 20 -msec presses alternately applied to the distal pads of the index and the middle fingers of the subjects' left hand, with each sequence involving a brief press presented first to one finger (e.g., the index finger), then to the other finger (e.g., the middle finger), and finally to both fingers. Task ${ }_{2}$ was the unspeeded report of the location (i.e., index or middle finger) of the first press in the $T_{2}$ tactile sequence. A staircase procedure was devised in order to track subjects' performance in the tactile Task $_{2}$ and constrain the overall level of Task 2 accuracy at the longest SOA between $60 \%$ and $85 \%$.

\section{Method}

Subjects. Twenty students at the University of Padua volunteered to participate in the present experiment. Most were undergraduate students, and a few were graduate students or staff, with ages ranging from 21 to 29 years. All were naive as to the purpose of the experiment, and all reported normal taction and normal hearing. None of them had participated in Experiment 1.

Auditory stimuli. The auditory stimuli were the same as those used in Experiment 1.

Tactile stimuli. The tactile stimuli were two alternated sequences of presses applied to the distal pads of the index and the middle fingers of the left hand. The same apparatus for the generation and control of the tactile sequences as that used in Experiment 1 was used in the present experiment. Each sequence began with a 20-msec press applied to one fingerpad (e.g., that of the middle finger), followed by a blank interval of a variable temporal duration (see below). After the blank interval, a 20-msec press was applied to the other fingerpad (e.g., that of the index finger), followed by a blank interval of the same temporal duration as that of the preceding blank interval. The sequence terminated with a $20-\mathrm{msec}$ press applied to both fingerpads. The two sequences differed with respect to which finger was stimulated first- that is, one sequence began with the stimulation of the index finger, and the other sequence began with the stimulation of the middle finger.

Procedure. The subjects were seated with both arms resting on the table in front of them, facing a computer monitor. On each trial 
of the present experiment, one auditory stimulus, $\mathrm{T}_{1}$, and one sequence of tactile stimuli, $\mathrm{T}_{2}$, were presented in succession. Each trial began with the presentation of a fixation cross at the center of the monitor, which remained on the screen during the entire trial. A research assistant initiated each trial by pressing a key on a response box. After this keypress, a fixed temporal interval of $600 \mathrm{msec}$ elapsed before the presentation of $\mathrm{T}_{1}$. Half of the subjects were instructed to make an immediate, vocal, two-alternative choice response based on the pitch of $\mathrm{T}_{1}$ by saying "high" if the pitch of $\mathrm{T}_{1}$ was high or "low" if the pitch of $\mathrm{T}_{1}$ was low (the $\mathrm{T}_{1}$ respond condition). Vocal RTs were measured as in Experiment 1. The auditoryvocal task, Task ${ }_{1}$, was defined as the primary task in the instructions, and the research assistant scored the vocal responses for accuracy during the entire experiment. The other half of the subjects were instructed to ignore $\mathrm{T}_{1}$ (the $\mathrm{T}_{1}$ ignore condition). ${ }^{3}$

At one of three possible SOAs (100, 250, or $900 \mathrm{msec})$ following the tone, $T_{2}$ was presented. The subjects in both $T_{1}$ conditions were instructed to make an unspeeded, manual, two-alternative choice response based on the starting location of $\mathrm{T}_{2}$. The subjects pressed the "1" key of the numeric keypad on the computer keyboard if the $\mathrm{T}_{2}$ sequence of tactile stimuli started with the stimulation of the middle finger or the " 2 " key if the $\mathrm{T}_{2}$ sequence of tactile stimuli started with the stimulation of the index finger. Presses to " 1 " and " 2 " keys were made by using the right hand. The subjects were instructed to perform the tactile-manual task, Task ${ }_{2}$, as accurately as they could and were discouraged from treating Task ${ }_{2}$ as a speeded task. Indeed, the subjects were informed that the computer program would not accept manual responses for a period of $1.5 \mathrm{sec}$ immediately following the vocal response.

Two types of sessions preceded the data-recording session. The subjects in the $\mathrm{T}_{1}$ respond condition performed a microphone sensitivity adjustment block of trials as described in Experiment 1 . The second session was dedicated to practice for the actual experiment. The subjects performed eight blocks of eight trials in their respective $\mathrm{T}_{1}$ condition. During this session, the blank temporal duration within the $\mathrm{T}_{2}$ tactile sequence was adjusted to bring the subjects' accuracy to about $75 \%$, using the following procedure. In the first four blocks of practice trials, the SOA between $T_{1}$ and $T_{2}$ was always $900 \mathrm{msec}$. In the second four blocks, $\mathrm{T}_{2}$ was presented at the shortest and longest SOAs. Each subject's mean accuracy in Task ${ }_{2}$ was computed at the end of each block only for trials at the longest SOA. The blank duration for $\mathrm{T}_{2}$ (set initially to $100 \mathrm{msec}$ ) was lengthened by $15 \mathrm{msec}$ if Task $\mathrm{k}_{2}$ accuracy was below $60 \%$ or was shortened by $30 \mathrm{msec}$ if Task $_{2}$ accuracy was above $85 \%$. Within each block of trials, the blank interval duration for $\mathrm{T}_{2}$ was constant. This staircase procedure continued to be applied throughout the entire experiment, using the mean accuracy level in Task ${ }_{2}$ at the longest SOA in the previous block of trials to adjust the $\mathrm{T}_{2}$ blank interval duration for the next block of trials.

At the end of the practice session, the instructions were repeated, and each subject performed 10 blocks of 24 trials each. Levels of SOA, tone frequency, and $\mathrm{T}_{2}$ starting location were fully crossed within each block of trials. At the end of each experimental block, the subjects in the $T_{1}$ respond condition were provided with feedback on their mean Task 1 RT and mean Task ${ }_{2}$ accuracy. The subjects in the $\mathrm{T}_{1}$ ignore condition were provided with feedback on their mean Task $_{2}$ accuracy. Feedback was provided through written information reported on the computer monitor.

\section{Results}

The analyses concentrated on correct RTs and error rates in $\mathrm{Task}_{1}$ (i.e., in the $\mathrm{T}_{1}$ respond condition) and ac-

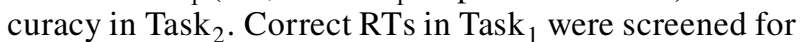
outliers, using the same procedure as that in Experiment 1 , which resulted in the loss of $2.0 \%$ of the correct
RTs. The results from both tasks were analyzed with an ANOVA, in which SOA was treated as a within-subjects variable and $\mathrm{T}_{1}$ condition as a between-subjects variable.

Task $_{1}$. Mean $\mathrm{RT}_{1} \mathrm{~s}$ at the shortest, medium, and longest SOAs were 466,421 , and $470 \mathrm{msec}$, respectively. The SOA effect was significant $\left[F(2,18)=6.2, M S_{\mathrm{e}}=1,170\right.$, $p<.01$ ], reflecting the mean $\mathrm{RT}_{1}$ at the intermediate SOA that was $40 \mathrm{msec}$ shorter than those at the shortest and longest SOAs.

The mean error rate in Task ${ }_{1}$ was $5 \%$. The SOA effect was significant $\left[F(2,18)=5.1, M S_{\mathrm{e}}=0.001, p<.02\right]$, indicating a slightly higher error rate at the two shorter SOAs $(5.5 \%)$, as compared with the error rate at the longest SOA $(4.5 \%)$.

Task $_{2}$. Mean proportions of correct responses in Task 2 , as a function of SOA and $\mathrm{T}_{1}$ condition, are plotted in Figure 2 . The main effects of SOA and $\mathrm{T}_{1}$ condition were both significant $\left[F(2,36)=30.1, M S_{\mathrm{e}}=0.003, p<.001\right.$, and $F(1,18)=8.2, M S_{\mathrm{e}}=0.01, p<.02$, respectively]. There was an overall decrease in accuracy as SOA was shortened. The subjects were more accurate in the $\mathrm{T}_{1}$ ignore condition than in the $\mathrm{T}_{1}$ respond condition. A significant interaction between SOA and $\mathrm{T}_{1}$ condition $[F(2,36)=7.7$, $\left.M S_{\mathrm{e}}=0.002, p<.01\right]$ provided statistical support for the clear pattern of results visible in Figure 2. SOA effects were more marked in the $T_{1}$ respond condition (square symbols) than in the $\mathrm{T}_{1}$ ignore condition (circular symbols). The $5 \%$ decrease in accuracy across SOAs in the $\mathrm{T}_{1}$ ignore condition produced a significant SOA effect in a separate analysis in which only the data from the $\mathrm{T}_{1}$ ignore condition were included in the analysis of proportion of correct responses $\left[F(1,18)=5.0, M S_{\mathrm{e}}=0.002, p<.02\right]$.

A significant interaction between SOA and $\mathrm{T}_{1}$ condition $\left[F(2,36)=6.9, M S_{\mathrm{e}}=0.100, p<.01\right]$ was found in a further analysis carried out on standard measures of sensitivity ( $d^{\prime}$; Green \& Swets, 1974), calculated by treating one stimulus category (i.e., index finger) as signal and the other stimulus category (i.e., middle finger) as noise. The $d^{\prime}$ values in each cell of the present experimental design are reported in Figure 2 (in parentheses). No effect was significant in the analysis carried out on $\beta$ values (mean $\beta=1.1$; all $F_{\mathrm{s}}<1$ ).

\section{Discussion}

The results of Experiment 2 revealed a tactile $A B$ effect in conditions in which Task ${ }_{1}$ required a speeded response to an unmasked auditory stimulus presented in $\mathrm{T}_{1}$ and Task $_{2}$ required the unspeeded report of the location of masked tactile stimulation presented in $\mathrm{T}_{2}$. When the subjects were instructed to respond to $\mathrm{T}_{1}$, RTs in Task were minimally affected by variations in the SOA between the two target stimuli, and accuracy in $\mathrm{Task}_{2}$ progressively decreased to a value that, at the shortest SOA, was very close to chance. As is typically reported in these paradigms, a close-to-nil $\mathrm{AB}$ effect was observed when $\mathrm{T}_{1}$ could be ignored (e.g., Dell'Acqua \& Jolicœur, 2000). 


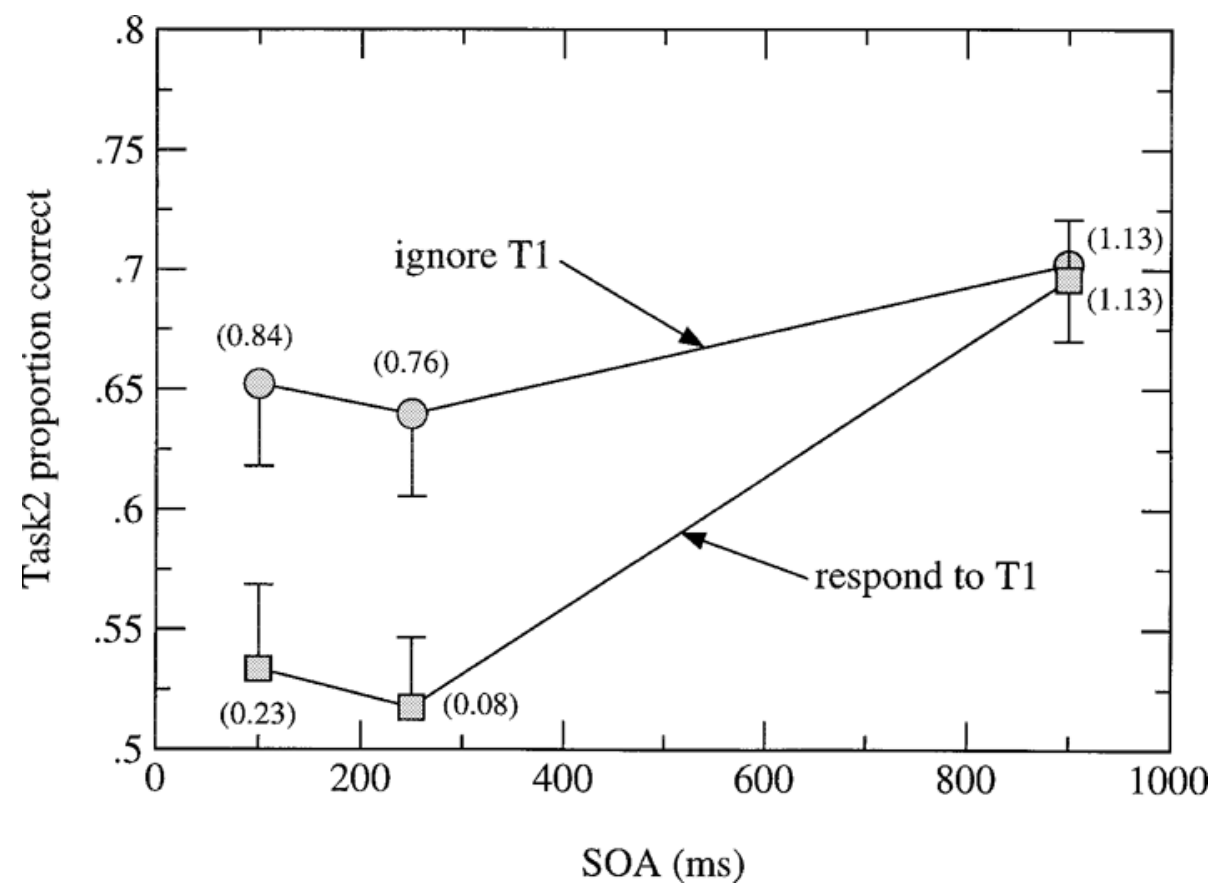

Figure 2. Results from Experiment 2: Mean proportion of correct location discrimination responses in the tactile-manual Task ${ }_{2}$, as a function of SOA and $T_{1}$ condition (ignore $T_{1} v s$. respond to $\mathrm{T}_{1}$ ). Values of $d^{\prime}$ are reported in parentheses. Vertical bars show standard errors of the mean.

\section{EXPERIMENT 3}

As was put forth in the introduction to the present study, the results of Experiment 2 are consistent with the hypothesis that the encoding of the masked tactile information required to perform Task $_{2}$ (i.e., stimulus location) relied on central mechanisms that are subject to interference from concurrent central processing of a stimulus presented in a different modality. Although explicitly predicted on the basis of the model sketch in the introduction, however, at least one alternative explanation of the present findings must be considered. It may be argued that the causal factor of the observed AB-like results of Experiment 2 was the specific requirement of a speeded response in Task ${ }_{1}$, whereas traditional AB effects, which are observed when the responses in both Task ${ }_{1}$ and Task 2 are unspeeded, would be caused by limiting factors functionally distinct from the central bottleneck generated by a speeded response. To rule out this possibility and further support the proposed link between PRP and AB effects, Experiment 3 was designed to minimize the differences between the variant of the $\mathrm{AB}$ paradigm used in Experiment 2 and more traditional $\mathrm{AB}$ experiments.

The requirement of unspeeded responses to both $T_{1}$ and $\mathrm{T}_{2}$ was implemented in Experiment 3 by using the same $\mathrm{T}_{2}$ (and Task ${ }_{2}$ ) as that used in Experiment 2 and replacing the auditory $\mathrm{T}_{1}$ with a visually presented digit embedded in an RSVP of letters that required an unspeeded odd/even decision. The purpose of Experiment 3 was, therefore, double-edged: We wished to generalize the findings of Experiment 2 to paradigms employing an unspeeded first task, while also generalizing these findings to a new combination of stimulus modalities (visual-tactile). If we were to find a tactile $\mathrm{AB}$ effect in Experiment 3, we would know that such an effect can be found even if Task 1 is not speeded, and we would have extended the range of possible modality combinations in which it is possible to find cross-modal $A B$ effects.

\section{Method}

Subjects. Twelve undergraduate students at the University of Padua, with ages ranging from 20 to 27 years, volunteered to participate in the present experiment. All were naive as to the purpose of the experiment, and all reported normal taction and normal or corrected-to-normal vision. None of them had participated in Experiment 1 or in Experiment 2.

Visual stimuli. The stimuli were black $\left(0.4 \mathrm{~cd} / \mathrm{m}^{2}\right)$ uppercase letters and white $\left(25 \mathrm{~cd} / \mathrm{m}^{2}\right)$ digits presented on a gray $\left(11 \mathrm{~cd} / \mathrm{m}^{2}\right)$ background on a SVGA color computer monitor controlled by a 686 CPU. The stimuli were presented in RSVP, at the same location at the center of the monitor, at a rate of $10 \mathrm{stimuli} / \mathrm{sec}$. Each stimulus was exposed for $100 \mathrm{msec}$ with no blank interstimulus interval and subtended $1^{\circ}$ of visual angle in height and in width at a distance of approximately $60 \mathrm{~cm}$. The set of letters included all of the letters of the English alphabet. The set of digits included all digits except 0 and 1 .

Tactile stimuli. The tactile stimuli were the same as those used in Experiment 2-that is, triplets of 20-msec presses applied to the distal pads of the index and the middle fingers of the left hand. The same apparatus for the generation and control of the tactile sequences as that used in Experiments 1 and 2 was used in the present experiment.

Procedure. The subjects were seated with both arms resting on the table in front of them, facing a computer monitor. On each trial 
of the present experiment, one visual stimulus, $T_{1}$, and one sequence of tactile stimuli, $\mathrm{T}_{2}$, were presented in succession. Both stimuli required unspeeded responses. A pair of horizontally arrayed plus signs $(++)$ was presented at the center of the screen, in green, at the beginning of each trial. The plus signs provided feedback on performance in the previous trial and acted as a fixation point in the current trial. The left plus sign indicated performance in Task ${ }_{1}$ (see below), and the right plus sign indicated performance in Task 2 . A plus sign indicated a correct performance, which was replaced with a minus sign in the case of an incorrect performance.

A research assistant initiated each trial by pressing a key on a response box. This press caused the fixation signs to disappear and, at a fixed interval of $600 \mathrm{msec}$ after the fixation signs offset, the onset of the RSVP stream. On each trial, there were from six to nine letter distractors prior to the presentation of one digit $\left(\mathrm{T}_{1}\right)$ and from 10 to 12 letter distractors following $\mathrm{T}_{1}$. The number of letter distractors prior to and following $T_{1}$ was selected randomly at run time. In half of the blocks of trials, the subjects were invited to make an unspeeded two-alternative choice response at the end of the RSVP, in order to indicate whether the $T_{1}$ digit was odd or even. The subjects were instructed to press the "7" key on the numeric keypad of the computer keyboard to respond odd or the " 8 " key to respond even. In the other half of the blocks of trials, the subjects were invited to ignore $T_{1}$ and were strongly encouraged to keep on looking at the RSVP on the screen. Trials in which the subjects were not looking at the center of the screen while performing in the $T_{1}$ ignore condition were marked by the research assistant with a press of a key on the response box. The subjects alternated between Task conditions (respond to $\mathrm{T}_{1}$ vs. ignore $\mathrm{T}_{1}$ ) from block to block. The type of starting block was counterbalanced across subjects.

At one of three possible SOAs $(100,250$, or $900 \mathrm{msec})$ following $\mathrm{T}_{1}, \mathrm{~T}_{2}$ was presented, and the subjects were instructed to make an unspeeded two-alternative choice response based on the starting location of $T_{2}$. The subjects pressed the "1" key of the numeric keypad on the computer keyboard if the $T_{2}$ sequence of tactile stimuli started with the stimulation of the middle finger or the " 2 " key if the $\mathrm{T}_{2}$ sequence of tactile stimuli started with the stimulation of the index finger. Presses to " 1 " and " 2 " keys were made with the right hand. The response for Task ${ }_{2}$ was always performed after the response for Task ${ }_{1}$, when Task ${ }_{1}$ required a response.

The subjects performed 4 blocks of 16 practice trials before the beginning of the actual experiment. The first 2 blocks were dedicated to practice in the $\mathrm{T}_{1}$ ignore condition. The second 2 blocks were dedicated to practice in the $\mathrm{T}_{1}$ respond condition. In all of the practice blocks, only trials in which the SOA between $T_{1}$ and $T_{2}$ was either 100 or $900 \mathrm{msec}$ were presented. Each subject's mean accuracy in Task $_{2}$ was computed at the end of each block only for trials at the longest SOA, and this variable was used to adjust the blank temporal duration within the $\mathrm{T}_{2}$ tactile sequence to constrain the subjects' accuracy between $60 \%$ and $85 \%$, using the same staircase procedure as that described in Experiment 2. The staircase procedure, which was duplicated independently for the two Task ${ }_{1}$ conditions, continued to be applied throughout the entire experiment, using the mean accuracy level in Task ${ }_{2}$ at the longest SOA in the previous block of trials in a given Task ${ }_{1}$ condition to adjust the $T_{2}$ blank interval duration for the next block of trials in the same Task ${ }_{1}$ condition. Within each block of trials, the blank interval duration for $\mathrm{T}_{2}$ was held constant. At the end of the practice blocks, the instructions were repeated, and each subject performed 12 blocks of 24 trials each. Each block was preceded by written instructions as to the type of task to perform on $\mathrm{T}_{1}$. Levels of SOA, evenness/oddness of $\mathrm{T}_{1}$, and $\mathrm{T}_{2}$ starting location were fully crossed within each block of trials. At the end of each experimental block, the subjects were provided with feedback on their mean Task ${ }_{1}$ accuracy (in the $\mathrm{T}_{1}$ respond condition only) and mean Task $\mathrm{k}_{2}$ accuracy. Feedback was provided through written information reported on the computer monitor.

\section{Results}

The analyses concentrated on the proportion of correct responses in Task $_{1}$ (i.e., in the $\mathrm{T}_{1}$ respond condition) and on the proportion of correct responses in $\mathrm{Task}_{2}$ con-

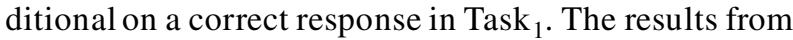
both tasks were analyzed with an ANOVA, in which SOA and $\mathrm{T}_{1}$ condition were treated as within-subjects factors. $\mathrm{T}_{1}$ ignore trials $(0.1 \%)$, in which subjects were not looking at the center of the screen during the RSVP of characters, were excluded from the analysis.

Task $_{1}$. In the $T_{1}$ respond condition, the mean proportion of correct responses was $94 \%$. From the shortest to the longest SOAs, the mean proportion of correct responses was $95 \%, 94 \%$, and $94 \%$, respectively. No effect

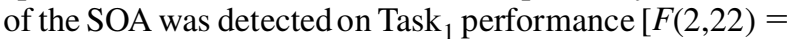
$1.0, p>.37]$.

Task $_{2}$. The mean proportion of correct responses in Task $_{2}$, as a function of SOA and $\mathrm{T}_{1}$ condition, is plotted in Figure 3. The main effects of SOA and $\mathrm{T}_{1}$ condition were both significant $\left[F(2,22)=26.8, M S_{\mathrm{e}}=0.005, p<\right.$ .001 , and $F(1,11)=22.8, M S_{\mathrm{e}}=0.009, p<.001$, respectively]. There was an overall decrease in accuracy as SOA was shortened. The subjects were globally more accurate in the $T_{1}$ ignore condition than in the $T_{1}$ respond condition. There was a significant interaction between SOA and $\mathrm{T}_{1}$ condition $\left[F(2,22)=11.1, M S_{\mathrm{e}}=0.003, p<\right.$ $.001]$. As is visible in Figure 3, SOA effects were more pronounced in the $\mathrm{T}_{1}$ respond condition (square symbols) than in the $T_{1}$ ignore condition (circular symbols). The lower accuracy that characterized Task $_{2}$ performance in the $\mathrm{T}_{1}$ ignore condition at the two shorter SOAs produced a significant SOA effect when the data from the $\mathrm{T}_{1}$ ignore condition were separately considered $[F(2,22)=$ $\left.4.4, M S_{\mathrm{e}}=0.004, p<.05\right]$.

A further analysis was carried out on standard measures of sensitivity calculated by treating one stimulus category (i.e., index finger) as signal and the other stimulus category (i.e., middle finger) as noise. The $d^{\prime}$ values in each cell of the present experimental design are reported in Figure 3 (in parentheses). The analysis carried out on $d^{\prime}$ revealed a significant interaction between SOA and $\mathrm{T}_{1}$ condition $\left[F(2,22)=6.5, M S_{\mathrm{e}}=0.143, p<.01\right]$. No factor effect was significant in the analysis carried out on $\beta$ values (mean $\beta=1.5$; all $F_{\mathrm{s}}<1$ ).

\section{Discussion}

Experiment 3 was designed to test whether the tactile $\mathrm{AB}$ effect observed in Experiment 2 was caused by the requirement of a speeded response in Task ${ }_{1}$. To test this hypothesis, a more classical $\mathrm{AB}$ paradigm was used in Experiment 3 , in which a visually presented $\mathrm{T}_{1}$ digit was embedded in an RSVP of letters requiring an unspeeded odd/even judgment. The results of Experiment 3 were clear-cut and convincingly ruled out the proposal of the speeded response for Task ${ }_{1}$ as the cause of the effects observed in Experiment 2. A robust tactile AB effect was found when Task ${ }_{1}$ required an unspeeded response (i.e., 


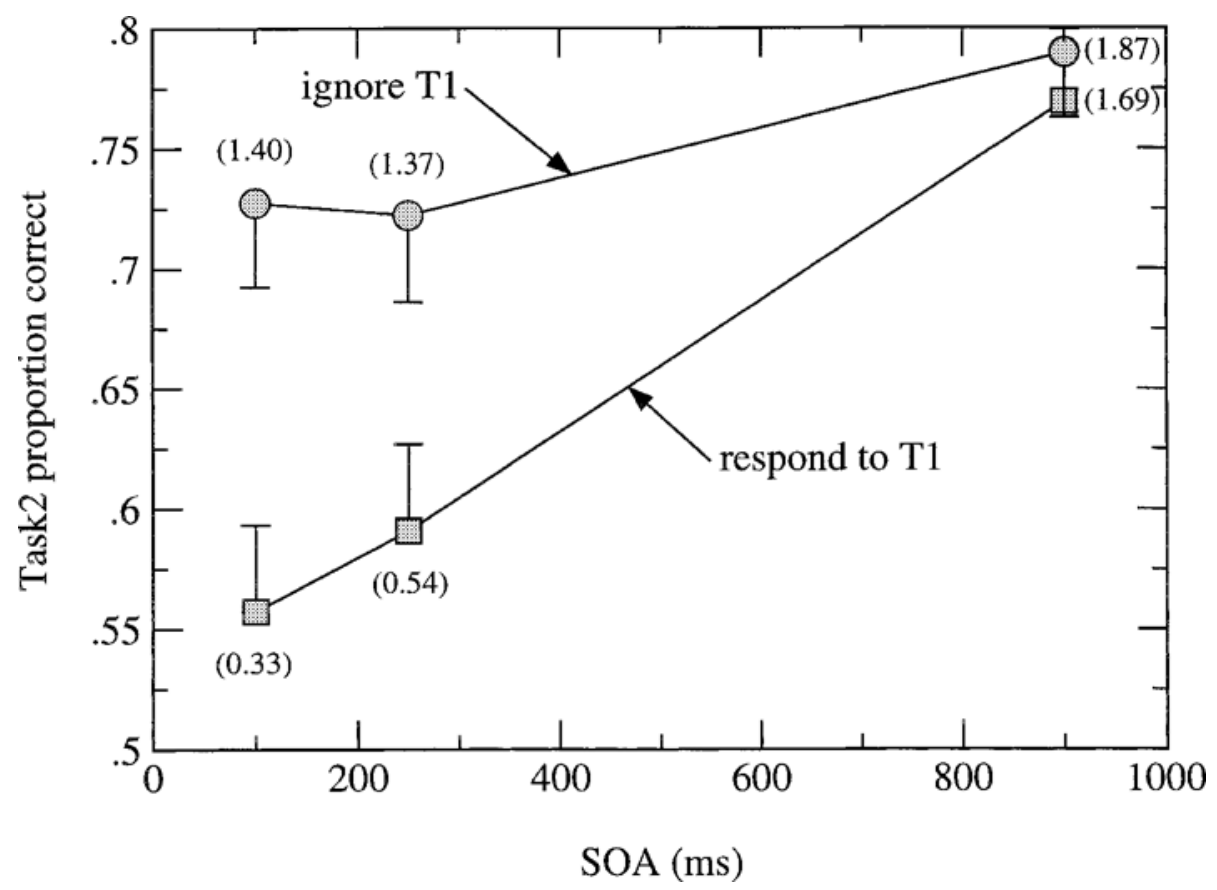

Figure 3. Results from Experiment 3: Mean proportion of correct location discrimination responses in the tactile-manual Task ${ }_{2}$, as a function of SOA and $T_{1}$ condition (ignore $T_{1}$ vs. respond to $T_{1}$ ). Values of $d^{\prime}$ are reported in parentheses. Vertical bars show standard errors of the mean.

in the $\mathrm{T}_{1}$ respond condition). The tactile $\mathrm{AB}$ was almost eliminated when $T_{1}$ could be ignored (i.e., in the $T_{1}$ ignore condition).

\section{EXPERIMENT 4}

A further possibility we wanted to check was whether the $\mathrm{AB}$ effects shown in Experiments 2 and 3 could have been due to a structural limitation affecting a central processing of the stimuli, as we hypothesize, or to a class of attentional limitations arising from a difference in the cognitive operations required to carry out Task ${ }_{1}$ and Task $_{2}$ (e.g., Potter et al., 1998; Rogers \& Monsell, 1995). It might be argued, indeed, that the need to reconfigure the task set in switching from Task to Task $_{2}$ was a determinant for the cross-modal ABs found in Experiments 2 and 3. In Experiment 2, $\mathrm{T}_{1}$ was a pure tone, and a speeded response was required that was based on its pitch. In Experiment $3, \mathrm{~T}_{1}$ was a visually presented digit that likely required identification for the unspeeded odd/even judgment. Both of these tasks were arguably different from the unspeeded report of the masked tactile stimulation that was presented in $T_{2}$. Per intended manipulation, there was a difference in the perceptual codes in which $T_{1}$ and $\mathrm{T}_{2}$ were presented. Furthermore, there was also an objective difference in the type of information presented in $\mathrm{T}_{1}$ and $\mathrm{T}_{2}$ (i.e., $\mathrm{T}_{1}$, tone pitch or digit identity; $\mathrm{T}_{2}$, spatial location), so that reconfiguring the attentional set between the tasks implemented in our paradigms may be a viable hypothesis, on the assumption that even the cognitive operations involved in $\mathrm{T}_{1}$ and $\mathrm{T}_{2}$ processing were (at least partly) different.

Experiment 4 was intended as a first-step approximation to a paradigm in which task-switch costs and $A B$ costs could be disentangled. The paradigm used in Experiment 4 was very similar to the paradigm used in Experiment 3 , with the exception that $\mathrm{T}_{1}$ (i.e., the digit) was presented unpredictably on $50 \%$ of the trials within each experimental block. On trials in which $\mathrm{T}_{1}$ was presented, the subjects were required to make an unspeeded odd/ even judgment at the end of the RSVP of characters. On trials in which $\mathrm{T}_{1}$ was absent, the subjects had to press the space bar to skip Task ${ }_{1}$ and continue with Task ${ }_{2}$ - namely, the unspeeded report of the tactile stimulation location.

Given that $T_{1}$ was presented unpredictably from trial to trial, we assume that the subjects adopted a task set optimized for the processing of $T_{1}$ at the onset of each trial. Such a task set would be required in order to perform Task $_{1}$ with high accuracy, on those trials in which $\mathrm{T}_{1}$ was presented. On trials in which $\mathrm{T}_{1}$ was not presented, however, the subjects would need to abandon this initial task set for $\mathrm{T}_{1}$ and switch to a task set more appropriate for $T_{2}$, in order to process $T_{2}$ effectively. Consequently, if the only source of interference causing a performance deficit in Task $_{2}$ is associated with switching from a set with which to process $T_{1}$ to a set with which to process $T_{2}$, the $A B$ effects in $T_{1}$-present and $T_{1}$-absent trials should be identical, since both trials should involve 
an initial task set with which to process $T_{1}$ followed by a switch to a set with which to process $\mathrm{T}_{2}$. Performance on $\mathrm{T}_{1}$-absent trials might, perhaps, even be worse than that on $\mathrm{T}_{1}$-present trials, because subjects might delay switching from the $\mathrm{T}_{1}$ task set to the $\mathrm{T}_{2}$ task set to a later frame in the RSVP sequence as the trial progressed, in case $\mathrm{T}_{1}$ were to arrive in a later RSVP frame. In contrast, the actual presentation of $T_{1}$ provides an effective cue to the subject that the task set for $\mathrm{T}_{2}$ should be activated. On the other hand, if executing the cognitive processes required to process $T_{1}$, per se, plays a causal role in the observed cross-modal $A B$ effect, the $A B$ effect in the $T_{1^{-}}$ present trials should be larger than the $\mathrm{AB}$ effect in the $\mathrm{T}_{1}$-absent trials. That was the prediction of the centralinterference model sketched in the introduction.

\section{Method}

Subjects. Fifteen graduate and undergraduate students at the University of Padua, with ages ranging from 22 to 31 years, volunteered to participate in the present experiment. All were naive as to the purpose of the experiment, and all reported normal taction and normal or corrected-to-normal vision. None of them had participated in any of the experiments described earlier in the present paper.

Visual stimuli. The same visual stimuli as those used in Experiment 3 were used in the present experiment.

Tactile stimuli. The same tactile stimuli and the same apparatus for the generation and control of the tactile sequences as those used in Experiments 1-3 were used in the present experiment.

Procedure. The subjects were seated with both arms resting on the table in front of them, facing a computer monitor. A pair of horizontally arrayed plus signs (++) was presented at the center of the screen, in green, at the beginning of each trial. The plus signs acted as fixation and feedback, as was described in Experiment 3.

A research assistant initiated each trial by pressing a key on a response box. This press caused the fixation signs to disappear and, at a fixed interval of $600 \mathrm{msec}$ after the fixation signs offset, the onset of the RSVP stream. The experiment was organized in 12 blocks of 24 trials each. Within each block of trials, $T_{1}$ (the white digit) was presented on $50 \%$ of the trials, with .5 probability on each trial. In the other $50 \%$ of the trials in a block, $T_{1}$ was replaced with a (randomly chosen) black letter distractor, which acted as the temporal marker for the calculation of the SOA at which to present $\mathrm{T}_{2}$. There were from 6 to 9 letter distractors prior to the presentation of $T_{1}$ (or the letter distractor replacing $T_{1}$ ) and from 10 to 12 letter distractors following $\mathrm{T}_{1}$. The number of letter distractors prior to and following $\mathrm{T}_{1}$ was selected randomly at run time. On $\mathrm{T}_{1^{-}}$ present trials, the subjects were invited to make an unspeeded twoalternative choice response at the end of the RSVP, in order to indicate whether the $T_{1}$ digit was odd or even. The subjects were instructed to press the "7" key on the numeric keypad of the computer keyboard to respond $o d d$, or the " 8 " key to respond even. On $\mathrm{T}_{1}$-absent trials, the subjects were invited to press the space bar and continue with Task 2 .

At a 100-, 250-, or 900-msec SOA following $\mathrm{T}_{1}$ (or its replacement), $T_{2}$ was presented, and the subjects were instructed to make an unspeeded two-alternative choice response based on the starting location of $\mathrm{T}_{2}$. The subjects pressed the " 1 " key of the numeric keypad on the computer keyboard if the $T_{2}$ sequence of tactile stimuli started with the stimulation of the middle finger or the " 2 " key if the $\mathrm{T}_{2}$ sequence of tactile stimuli started with the stimulation of the index finger. Presses to " 1 " and " 2 " keys were made with the right hand. The response for Task 2 was always performed after the response for Task 1 .
The subjects performed two blocks of 16 practice trials before the beginning of the actual experiment. In all of the practice blocks, only trials in which the SOA between $\mathrm{T}_{1}$ and $\mathrm{T}_{2}$ was either 100 or $900 \mathrm{msec}$ were presented. Each subject's mean accuracy in Task ${ }_{2}$ was computed at the end of each block only for trials at the longest SOA, and this variable was used to adjust the blank temporal duration within the $\mathrm{T}_{2}$ tactile sequence to constrain subjects' accuracy between $60 \%$ and $85 \%$, using the same staircase procedure as that described in Experiments 2 and 3. The staircase procedure continued to be applied throughout the entire experiment, using the mean accuracy level in Task ${ }_{2}$ at the longest SOA in the previous block of trials in a given Task $_{1}$ condition to adjust the $\mathrm{T}_{2}$ blank interval duration for the next block of trials in the same Task ${ }_{1}$ condition. Within each block of trials, the blank interval duration for $T_{2}$ was held constant. At the end of the practice blocks, the instructions were repeated, and the subjects performed the experimental blocks of trials. Levels of SOA, absence/presence of $\mathrm{T}_{1}$, evenness/oddness of $\mathrm{T}_{1}$, and $\mathrm{T}_{2}$ starting location were fully crossed within each block of trials. At the end of each experimental block, the subjects were provided with feedback on their mean Task ${ }_{1}$ accuracy (in the $\mathrm{T}_{1}$ present condition only) and mean Task ${ }_{2}$ accuracy. Feedback was provided through written information reported on the computer monitor.

\section{Results}

The analyses concentrated on the proportion of correct responses in Task $_{1}$ (in the $\mathrm{T}_{1}$-present condition) and on the proportion of correct responses in Task $\mathrm{k}_{2}$ conditional

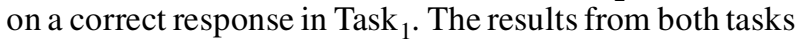
were analyzed with an ANOVA, in which SOA and $\mathrm{T}_{1}$ absence/presence were treated as within-subjects factors.

Task $_{1}$. In the $\mathrm{T}_{1}$-present condition, the mean proportion of correct odd versus even judgments was $95 \%$. From the shortest to the longest SOAs, the mean proportions of correct responses in $\mathrm{Task}_{1}$ were $96 \%, 95 \%$, and $95 \%$, respectively. No effect of the SOA was detected on Task $_{1}$ performance $(F<1)$.

Task $_{2}$. The mean proportion of correct responses in Task $_{2}$, as a function of SOA and $\mathrm{T}_{1}$ presence/absence, is plotted in Figure 4 . The main effects of SOA and $\mathrm{T}_{1}$ condition were both significant $\left[F(2,28)=48.8, M S_{\mathrm{e}}=\right.$ $0.002, p<.001$, and $F(1,14)=11.1, M S_{\mathrm{e}}=0.009, p<.01$, respectively]. There was an overall decrease in accuracy as SOA was shortened. The subjects were globally more accurate in the $\mathrm{T}_{1}$-absent condition than in the $\mathrm{T}_{1}$-present condition. There was a significant interaction between SOA and $\mathrm{T}_{1}$ condition $\left[F(2,28)=11.1, M S_{\mathrm{e}}=0.003\right.$, $p<.001]$. As Figure 4 shows, SOA effects were more pronounced in the $\mathrm{T}_{1}$-present condition (square symbols) than in the $\mathrm{T}_{1}$-absent condition (circular symbols). The

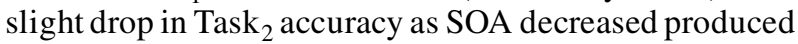
a significant effect when the data from the $\mathrm{T}_{1}$-absent condition were considered separately $[F(2,28)=9.8$, $\left.M S_{\mathrm{e}}=0.003, p<.01\right]$. An analysis restricted to the data set from the shortest SOA condition revealed no effect of $\mathrm{T}_{1}$ condition on the proportion of correct Task $\mathrm{S}_{2}$ responses $\left[F(1,14)=2.0, M S_{\mathrm{e}}=0.011, p>.17\right]$.

A further analysis was carried out on standard measures of sensitivity calculated by treating one stimulus category (i.e., index finger) as signal and the other stim- 


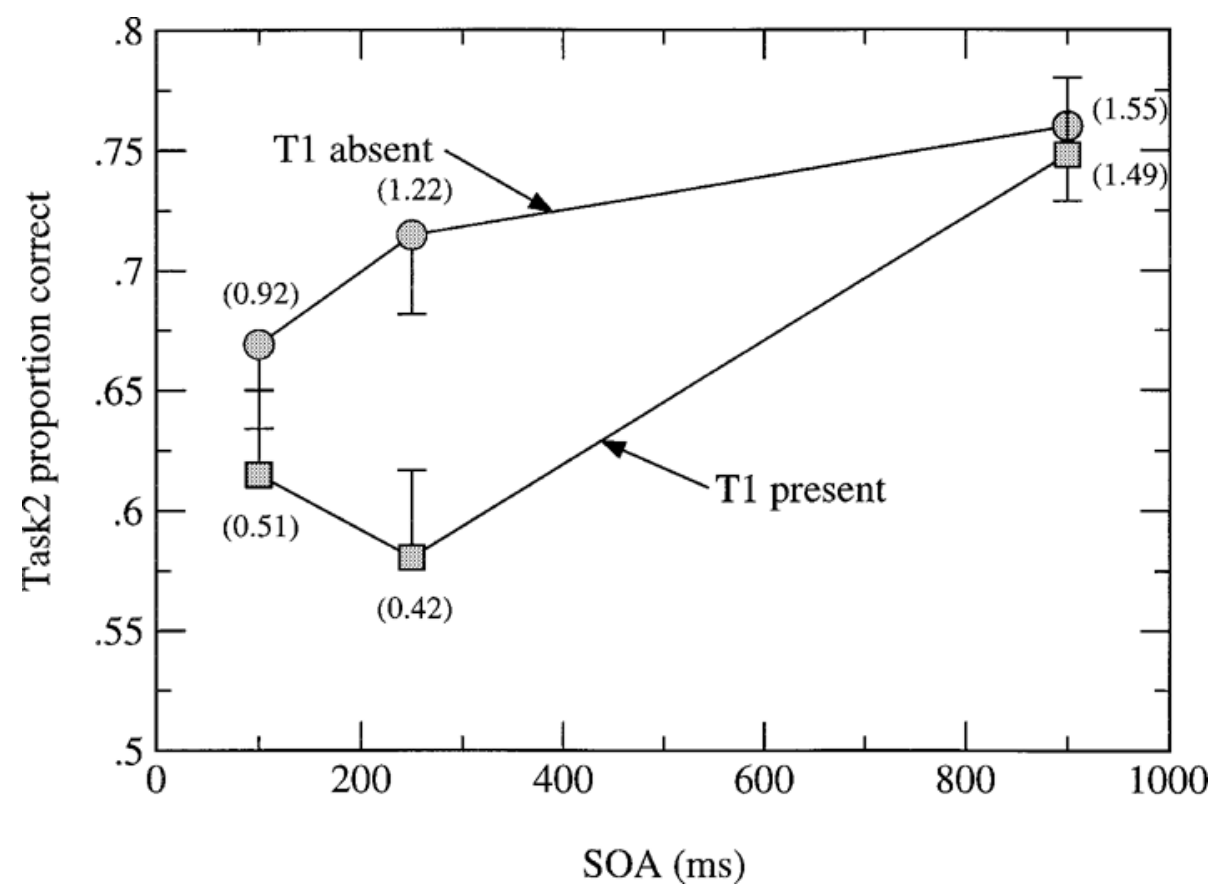

Figure 4. Results from Experiment 4: Mean proportion of correct location discrimination responses in the tactile-manual Task ${ }_{2}$, as a function of SOA and $T_{1}$ condition $\left(T_{1}\right.$ present vs. $T_{1}$ absent). Values of $d^{\prime}$ are reported in parentheses. Vertical bars show standard errors of the mean.

ulus category (i.e., middle finger) as noise. The $d^{\prime}$ values in each cell of the present experimental design are reported in Figure 4 (in parentheses). The analysis carried out on $d^{\prime}$ revealed a significant interaction between SOA and $\mathrm{T}_{1}$ condition $\left[F(2,28)=4.8, M S_{\mathrm{e}}=0.192, p<.01\right]$. An analysis restricted to the data set from the shortest SOA condition revealed no effect of $\mathrm{T}_{1}$ condition on $d^{\prime}$ $\left[F(1,14)=1.9, M S_{\mathrm{e}}=0.341, p>.19\right]$. No factor effect was significant in the analysis carried out on $\beta$ values (mean $\beta=1.3$; all $F_{\mathrm{s}}<1$ ).

\section{Discussion}

Task-switch costs have been reported in conditions in which two stimuli were presented serially and different tasks, usually cued by the nature of the stimuli, had to be performed in succession. These costs were manifest in the reduced performance on the first trial of a new task, as compared with the trial in which the task was repeated (e.g., Allport, Styles, \& Hsieh, 1994; Rogers \& Monsell, 1995). Experiment 4 was designed to investigate whether the cross-modal $\mathrm{AB}$ effects reported in Experiments 2 and 3 could be compared with task-switch costs. In Experiment 4 , the visual $\mathrm{T}_{1}$ (i.e., the digit) employed in Experiment 3 was presented with .5 probability on each trial. On the basis of $\mathrm{T}_{1}$ unpredictability, we argued that the subjects would initiate each trial set to process $\mathrm{T}_{1}$, independently on the actual occurrence of $\mathrm{T}_{1}$ in the RSVP sequence of letters. This was directly supported by the results of Task ${ }_{1}$. On $T_{1}$-present trials, the subjects were particularly accurate ( $95 \%$ correct responses) in making the unspeeded odd/even decision at the end of the RSVP. More important, had a switch in attentional set been solely responsible for the cross-modal $\mathrm{AB}$ found in our paradigms, the actual occurrence of $T_{1}$ in the RSVP should have played no role in determining the probability of detecting the tactile $\mathrm{T}_{2}$. The results of Experiment 4 were in striking contrast with this prediction. The tactile $\mathrm{AB}$ effect was more pronounced when $T_{1}$ was present then when $\mathrm{T}_{1}$ was absent, a finding that cannot be accounted for by assuming an equivalence between the mechanisms mediating shifts in attentional sets and the mechanisms causing the cross-modal $\mathrm{AB}$ effects found in Experiments 2-4. Interestingly, however, we noted that performance in $\mathrm{Task}_{2}$ at the shortest SOA did not differ, whether $\mathrm{T}_{1}$ was presented before $T_{2}$ or not. In practice, a small (but significant) $\mathrm{AB}$ effect was associated with the control (i.e., $\mathrm{T}_{1}$-absent) condition, which attenuated more quickly than the $\mathrm{AB}$ generated by having to consolidate a perceptual representation of $T_{1}$ when $T_{1}$ was present. It is not clear to us why this occurred, even though, at present, we favor an explanation based on the putative role played by a switch in input filters from Task to Task $_{2}$, proposed by Visser, Bischof, and Di Lollo (1999). That is, it might be that the small $\mathrm{AB}$ effect found in the $\mathrm{T}_{1}$-absent condition reflected the cost in shifting from a perceptual filter set to process the visual $\mathrm{T}_{1}$ to a perceptual filter tuned to detect the location of the tactile $\mathrm{T}_{2}$, with this consequent cost being added, at short SOAs, to the cost generated by $\mathrm{T}_{1}$ consolidation in the experimental (i.e., $\mathrm{T}_{1}$-present) condition. 


\section{GENERAL DISCUSSION}

In the present investigation, we focused on dual-task processing interactions that occur when one stimulus, $\mathrm{T}_{1}$, is presented through the auditory or the visual modality, followed at brief temporal intervals by a second stimulus, $\mathrm{T}_{2}$, presented through the tactile modality. We measured these interactions in four paradigms, a classical PRP paradigm (Experiment 1), a speeded variant of the $A B$ paradigm (Experiment 2), and two unspeeded $A B$ paradigms (Experiments 3 and 4 ).

In Experiments 1 and 2, $\mathrm{T}_{1}$ was a pure tone that had either a low or a high pitch, and Task ${ }_{1}$ was to decide, as fast and accurately as possible, whether the tone had a low or a high pitch. An additional control condition was used in Experiment 2, in which the tone was to be ignored. In Experiment $1, \mathrm{~T}_{2}$ was a single press, applied to the distal pad of either of two fingers, requiring a speeded twoalternative decision. In Experiment 2, $\mathrm{T}_{2}$ was a rapid sequence of tactile stimuli applied to the distal pads of two fingers, and the task on $T_{2}$ was to decide which finger was stimulated first. In Experiment 3 , the auditory $\mathrm{T}_{1}$ was replaced with a visually presented digit embedded in an RSVP of letters in a paradigm that was otherwise similar to that used in Experiment 2. In Task ${ }_{1}$, the subject either made an unspeeded odd/even judgment on the digit or ignored the digit; Task $_{2}$ was an unspeeded decision about which finger was stimulated first in the tactile $T_{2}$ sequence. Experiment 4 was very similar to Experiment 3 , with the exception that the $\mathrm{T}_{1}$ digit was presented randomly on $50 \%$ of the trials. In all the paradigms, Task $_{1}$ performance was largely unaffected by SOA. In contrast, $\mathrm{Task}_{2}$ performance was worse at short SOAs than at long SOAs. In Experiment 1, a clear-cut PRP effect was found, in that Task $\mathrm{K}_{2} \mathrm{RT}$ increased as SOA decreased. In Experiments $2-4$, sizable tactile $A B$ effects were found, in that Task $_{2}$ response accuracy in all the paradigms was lower at short SOAs than at long SOAs. The AB effects were reduced sharply when the subjects were instructed to ignore $\mathrm{T}_{1}$ or when $\mathrm{T}_{1}$ was not presented. A complementary set of analyses, carried out on standard measures of sensitivity, helped further specify the nature of the $A B$ effects observed in these experiments. The reduction in Task ${ }_{2}$ accuracy across SOAs was accounted for entirely by a reduction in sensitivity to $T_{2}$ starting location, as was suggested by evident SOA effects on $d^{\prime}$, with no effects being due to bias, as was suggested by null effects on $\beta$.

The present results extend earlier work (e.g., Arnell \& Jolicœur, 1999; Dell' Acqua \& Jolicœur, 2000; Jolicœur et al., 2000; Ross \& Jolicœur, 1999) on the PRP and AB effects to paradigms in which one of two target stimuli is presented in a modality that, thus far, had largely been neglected by researchers in this field-namely, taction. To the extent that peripheral (i.e., sensory and/or motor) loci of dual-task interference may be ruled out in all the present paradigms, the proposed explanation of the present findings is as follows.
Like many others (e.g., McCann \& Johnston, 1992; Pashler, 1994; Van Selst \& Jolicœur, 1997), we assume that a stage of response selection, or a late stage of stimulus categorization just prior to response selection, requires capacity-limited central processing. Capacity limitations in central processing impose a forced seriality of processing between tasks. While Task ${ }_{1}$ engages the capacity-limited central mechanisms, these mechanisms are not available for processing in $\mathrm{Task}_{2}$. Consequently, processing in Task ${ }_{2}$ must wait for the mechanisms to be released by Task ${ }_{1}$. These assumptions predict that Task RTs should be elevated at short SOAs relative to those at long SOAs. This pattern of results was observed in Experiment 1.

Our model further assumes that a special operation, which we called short-term consolidation (Jolicœur \& Dell' Acqua, 1998), is to be included among the operations that require capacity-limited central mechanisms. Shortterm consolidation is required to encode information in short-term memory, and short-term memory was necessary for the execution of the unspeeded responses to the stimuli presented in Experiments 2-4. A growing body of evidence suggests that a capacity-limited stage of short-term consolidation is involved when briefly presented visual letters (Chun \& Potter, 1995) or spoken letters (Arnell \& Jolicœur, 1999) must be reported after a short delay. Assuming that short-term consolidation is also required for the unspeeded report of the starting location of a tactile sequence of stimuli, we hypothesized that, when a speeded response was required in Task ${ }_{1}$ (i.e., in the $T_{1}$ respond condition of Experiment 2), centralprocessing overlap between response selection in Task and short-term consolidation in Task ${ }_{2}$ would occur at short SOAs in Experiment 2. In this view, we argue that, in Experiment 2, response selection for $\mathrm{T}_{1}$ processing postponed short-term consolidation for $\mathrm{T}_{2}$ processing. As has been suggested for vision (Giesbrecht \& Di Lollo, 1998) and for audition (Arnell \& Jolicœur, 1999), this period of waiting for short-term consolidation causes the decay of tactile location information, under conditions in which tactile stimulation is not continuously supported by informational persistence at a sensory level (Jolicœur, 1998). One way to prevent persistence is to use tactile backward masking (e.g., Craig, 1989; Evans, 1987), a technique that was implemented in Experiments 2-4 by presenting $T_{2}$ as rapid serial tactile stimulation, in which the presentation of trailing stimuli was likely to be effective in annulling the functional usefulness of the persistence of information about the location of the first stimulated location in the $\mathrm{T}_{2}$ sequence. Although some (e.g., Evans, 1987) have argued that temporal integration is the prevailing cause of the reduced performance in tactile backward masking, Giesbrecht and Di Lollo have provided an elegant demonstration that some form of processing interruption must be engendered by masking for a visual $\mathrm{AB}$ to be observed. Whether masking of $\mathrm{T}_{2}$ in our paradigm was produced by temporal integration or interrup- 
tion is difficult to ascertain; however, what is clear is that

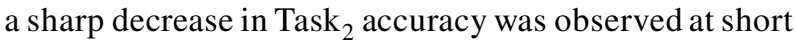
SOAs when response selection was required for $\mathrm{T}_{1}$ processing (i.e., in the $\mathrm{T}_{1}$ respond condition) in Experiment 2, a tactile $\mathrm{AB}$ effect.

Contrary to the suggestion that the $\mathrm{AB}$ observed in Experiment 2 could be due exclusively to the speeded nature of the response to $T_{1}$, and thoroughly consistent with the model discussed in the present context, we also found a tactile $\mathrm{AB}$ effect in Experiment 3-namely, upon presentation of a $T_{1}$ embedded in an RSVP stream of characters that was associated with an unspeeded Task ${ }_{1}$. In both Experiment 2 and Experiment 3, these $A B$ effects were reduced sharply when Task ${ }_{1}$ did not require processing of $\mathrm{T}_{1}$ (i.e., in the $\mathrm{T}_{1}$ ignore conditions).

The results of Experiment 4 are particularly important because we found a clear modulation of the tactile $A B$ effect by the presence versus absence of $\mathrm{T}_{1}$ in the RSVP stream. In Experiment 4, the visual $\mathrm{T}_{1}$ digit employed in Experiment 3 was presented with .5 probability on each trial, and Task ${ }_{1}$ was to make an (unspeeded) odd/even judgment based on $\mathrm{T}_{1}$ identity at the end of trials in which $\mathrm{T}_{1}$ was presented. The notably high accuracy with which the subjects performed Task ${ }_{1}$ strengthened our view that we were successful in inducing the subjects to initiate each trial set with which to process $T_{1}$, independently on its actual occurrence. Furthermore, a more pronounced $A B$ effect was found on $T_{1}$-present trials relative to $T_{1}$ absent trials. The model proposed herein provides a natural account of the results of Experiment 4. As was discussed above, our account relies on the hypothesis that crucial for the generation of the more sustained AB deficit observed in the $\mathrm{T}_{1}$-present condition was the type of processing $\mathrm{T}_{1}$ underwent following $\mathrm{T}_{1}$ presentation. On $\mathrm{T}_{1}$-present trials, $\mathrm{T}_{1}$ identity (or an abstract representation of the $\mathrm{T}_{1}$ "semantic" category) had to be encoded for the odd/even judgment that was performed at the end of the trial. We argue that this operation was carried out via short-term consolidation of the task-relevant information extracted from $\mathrm{T}_{1}$. As SOA decreased, the probability that short-term consolidation for Task 1 postponed short-term consolidation for Task ${ }_{2}$ increased. This timelocked interaction caused the progressive decay of the tactile representation of $T_{2}$ spatial location, which was manifest in the reduced Task ${ }_{2}$ accuracy at short SOAs.

What is the cause of the failure to find tactile AB effects that was reported by Shapiro et al. (1998)? We do not have a satisfactory answer to this question. Nonetheless, in a manuscript in preparation, in which the original experiments will be described in more detail (Hillstrom, Shapiro, \& Spence, 2000), we will have the opportunity to note several differences between our paradigms and theirs, among which one seems of particular importance. The tactile stimuli used in their investigation were vibrotactile stimuli, and the critical Task ${ }_{2}$ was to discriminate between target stimuli that were defined along the physical dimensions of frequency, duration, and location. Interestingly, the only AB effect they found was for tactile stimuli that differed in location, as the stimuli used in the present investigation were. The failure to find an $\mathrm{AB}$, per se, is a null result and invites the speculation that the sensitivity of the paradigms in which the frequency or the duration of the vibrotactile stimuli was manipulated was reduced by factors that have been shown to play a crucial role for detecting AB limitations. A central tenet of the model we have proposed, for instance, is that not only is $\mathrm{T}_{2}$ to be efficiently masked in $\mathrm{AB}$ paradigms, but it is also to be masked by interruption, so as to prevent the temporal persistence of the information presented in $\mathrm{T}_{2}$. If the $\mathrm{T}_{2}$ task-relevant information outlasts the period of processing suspension induced by concurrent $\mathrm{T}_{1}$ processing, an AB is not found (Giesbrecht \& Di Lollo, 1998; Jolicœur, 1999a). Indeed, when a tactile AB was not observed in Hillstrom et al.'s work, accuracy in the tactile tasks was always quite high (i.e., 75\%-85\%). Perhaps the cause of the failure to observe an $\mathrm{AB}$ effect with tactile stimuli varying in frequency or duration was the ineffective masking of $\mathrm{T}_{2}$. More work, however, will be required to test the validity of this hypothesis.

\section{REFERENCES}

Allport, D. A., Styles, E. A., \& Hsieh, S. (1994). Shifting intentional set: Exploring the dynamic control of tasks. In C. Umiltà \& M. Moscovitch (Eds.), Attention and performance XV: Conscious and nonconscious information processing (pp. 421-452). Cambridge, MA: MIT Press, Bradford Books.

Arnell, K. M., \& Jolicceur, P. (1999). The attentional blink across stimulus modalities: Evidence for central processing limitations. Journal of Experimental Psychology: Human Perception \& Performance, 25, 630-648.

Brebner, J. (1977). The search for exceptions to the psychological refractory period. In S. Dornic (Ed.), Attention and performance VI (pp. 63-78). Hillsdale, NJ: Erlbaum.

Broadbent, D. E., \& Broadbent, M. H. P. (1987). From detection to identification: Response to multiple targets in rapid serial visual presentation. Perception \& Psychophysics, 42, 105-113.

Chun, M. M. (1997). Types and tokens in visual processing: A double dissociation between the attentional blink and repetition blindness. Journal of Experimental Psychology: Human Perception \& Performance, 23, 738-755.

Chun, M. M., \& Potter, M. C. (1995). A two-stage model for multiple target detection in rapid serial visual presentation. Journal of Experimental Psychology: Human Perception \& Performance, 21, 109-127.

CraIG, J. C. (1989). Interference in localizing tactile stimuli. Perception \& Psychophysics, 45, 343-355.

DE JoNG, R. (1993). Multiple bottlenecks in overlapping task performance. Journal of Experimental Psychology: Human Perception \& Performance, 19, 965-989.

Dell'Acqua, R., \& Jolicceur, P. (2000). Visual encoding of patterns is subject to dual-task interference. Memory \& Cognition, 28, 184-191.

Duncan, J., Martens, S., \& WARD, R. (1997). Restricted attentional capacity within but not between sensory modalities. Nature, 387, 808-810.

Evans, P. M. (1987). Vibrotactile masking: Temporal integration, persistence, and strengths of representations. Perception \& Psychophysics, 42, 515-525.

Giesbrecht, B., \& Di Lollo, V. (1998). Beyond the attentional blink: Visual masking by object substitution. Journal of Experimental Psychology: Human Perception \& Performance, 24, 1454-1466.

GreEn, D. M., \& SwETS, J. A. (1974). Signaldetection theory and psychophysics. Huntington, NY: Krieger.

Hillstrom, A. P., Shapiro, K. L., \& Spence, C. (2000). Attentional and perceptual limitations in processing sequential vibrotactile targets. University of Texas at Arlington, Department of Psychology. Manuscript in preparation.

Joliceur, P. (1998). Modulation of the attentional blink by on-line re- 
sponse selection: Evidence from speeded and unspeeded Task ${ }_{1}$ decisions. Memory \& Cognition, 26, 1014-1032.

JOLICCEUR, P. (1999a). Dual-task interference and visual encoding. Journal of Experimental Psychology: Human Perception \& Performance, 25, 596-616.

JoLICEUR, P. (1999b). Restricted attentional capacity between sensory modalities. Psychonomic Bulletin \& Review, 6, 87-92.

Jolicceur, P., \& Dell'Acqua, R. (1998). The demonstration of shortterm consolidation. Cognitive Psychology, 36, 138-202.

Joliceur, P., Dell'Acqua, R., \& Crebolder,J. (2000). Multitasking performance deficits: Forging links between the attentional blink and the psychological refractory period. In S. Monsell \& J. Driver (Eds.), Attention and performance XVIII: Control of cognitive processes (pp. 309-330). Cambridge, MA: MIT Press.

KarLin, L., \& Kestenbaum, R. (1968). Effects of number of alternatives on the psychological refractory period. Quarterly Journal of Experimental Psychology, 20, 167-178.

McCann, R. S., \& Johnston, J. C. (1992). Locus of the single-channel bottleneck in dual-task interference. Journal of Experimental Psychology: Human Perception \& Performance, 18, 471-484.

Moore, C. M., Egeth, H., Berglan, L. R., \& Luck, S. J. (1996). Are attentional dwell times inconsistent with serial visual search? Psychonomic Bulletin \& Review, 3, 360-365.

PAshler, H. (1994). Dual-task interference in simple tasks: Data and theory. Psychological Bulletin, 116, 220-244.

Pashler, H., \& Johnston, J. C. (1989). Chronometric evidence for central postponement in temporally overlapping tasks. Quarterly Journal of Experimental Psychology, 41A, 19-45.

Pashler, H., \& Johnston, J. C. (1998). Attentional limitations in dualtask performance. In H. Pashler (Ed.), Attention (pp. 155-189). Hove, U.K.: Psychology Press.

Potter, M. C., Chun, M. M., Banks, B. S., \& Muckenhoupt, M. (1998). Two attentional deficits in serial target search: The attentional blink and an amodal task-switch deficit. Journal of Experimental Psychology: Learning, Memory, \& Cognition, 24, 979-992.

Raymond, J. E., Shapiro, K. L., \& Arnell, K. M. (1992). Temporary suppression of visual processing in an RSVP task: An attentional blink? Journal of Experimental Psychology: Human Perception \& Performance, 18, 849-860.

Raymond, J. E., Shapiro, K. L., \& Arnell, K. M. (1995). Similarity determines the attentional blink. Journal of Experimental Psychology: Human Perception \& Performance, 21, 653-662.

Rogers, R. D., \& Monsell, S. (1995). Costs of a predictable switch between simple cognitive tasks. Journal of Experimental Psychology: General, 124, 207-231.

Ross, N., \& Jolicceur, P. (1999). Attentional blink for color. Journal of Experimental Psychology: Human Perception \& Performance, 25, 1483-1494.

Schubert, T. (1999). Processing differences between simple and choice reactions affect bottleneck localization in overlapping tasks. Journal of Experimental Psychology: Human Perception \& Performance, 25, 408-425.

Shapiro, K. L., Hillstrom, A., \& Spence, C. (1998, November). Is there an attentional blink in taction? Paper presented at the 39th Annual Meeting of the Psychonomic Society, Dallas.
Shulman, H., \& Hsieh, V. (1995, November). The attentional blink in mixed modality streams. Paper presented at the 36th Annual Meeting of the Psychonomic Society, Los Angeles.

Telford, C. W. (1931). The refractory phase of voluntary and associative responses. Journal of Experimental Psychology, 14, 1-35.

VAn SElst, M., \& Jolicceur, P. (1994). A solution to the effect of sample size on outlier elimination. Quarterly Journal of Experimental Psychology, 47A, 631-650.

VAN Selst, M., \& Jolicceur, P. (1997). Decision and response in dualtask interference. Cognitive Psychology, 33, 266-307.

Van Selst, M., Ruthruff, E. \& Johnston, J. C. (1999). Can practice eliminate the psychological refractory period effect? Journal of Experimental Psychology: Human Perception \& Performance, 25, $1268-1283$

Visser, T. A. W., Bischof, W. F., \& Di Lollo, V. (1999). Attentional switching in spatial and nonspatial domains: Evidence from the attentional blink. Psychological Bulletin, 125, 458-469.

\section{NOTES}

1. According to the characteristics of the solenoid reported in the RS products catalogue, the delay between solenoid stimulation and plunger movement initiation is $2 \mathrm{msec}$. For this reason, the actual SOA values in both Experiment 1 and Experiment 2 were 102, 252, and 902 msec. For simplicity, and for the negligibility of these differences, however, we prefer to report the results of the present investigation in relation to the "round" SOA values.

2. For each task, the data in each cell were sorted, and the most extreme observation was temporarily excluded from consideration. The mean $(M)$ and standard deviation $(S D)$ of the remaining data points were then computed. Cutoff values were established using the following equations:

$$
V_{\text {low }}=M-C * S D
$$

and

$$
V_{\text {high }}=M+C * S D,
$$

where $C$ is a parameter that depended on sample size (see Van Selst \& Jolicœur, 1994), so that the final estimate of sample means was not influenced by sample size. The smallest and largest observations were then checked against the cutoff values and were treated as outliers if one or both of these data points were outside the bounds. If an outlier was found, the algorithm was applied anew to the remaining data points

3. This between-subjects manipulations of Task ${ }_{1}$ type was aimed at maximizing the number of trials performed by different subjects in each Task $_{1}$ condition of the present experiment. The between-subjects manipulation of Task ${ }_{1}$ type was abandoned in Experiments 3 and 4 in favor of a within-subjects manipulation of the same factor following the increase in the number of trials the subjects had to perform in each Task ${ }_{1}$ condition.

(Manuscript received February 17, 2000; revision accepted for publication October 12,2000.) 